\title{
MULTICULTURAL EDUCATION IN CIVIL ENGINEERING: PLANNING AND TRANSPORTATION APPROACH
}

\author{
B. Santos ${ }^{1}$, A. Virtudes ${ }^{1}$, J. Gonçalves ${ }^{1}$, S. Amin ${ }^{2}$ \\ ${ }^{1}$ University of Beira Interior (PORTUGAL) \\ ${ }^{2}$ Coventry University (UNITED KINGDOM)
}

\begin{abstract}
This article aims to present a comparative analysis of the practices of the University of Beira Interior in Covilhã (Portugal) and the Coventry University in the United Kingdom in terms of learning and teaching methodologies in a multicultural environment (including teachers' international experiences and students' backgrounds). The research is focused on the spatial planning and transportation engineering approaches, on the behalf of the Master Degree in Civil Engineering. A pivotal attention will be put at the use of information and communication technologies aiming to improve the students' digital literacy and their required level of internationalization.
\end{abstract}

Regarding the experience of the University of Beira Interior the conclusions show that its multicultural environment is essential a result of the presence of students from the Portuguese speaking countries (African countries, Brazil or East Timor). However, they are the basis of one of the main challenges in terms of teaching methodologies related to their lack of skills in English language.

Coventry University has been experiencing the similar multicultural diversity enrolling postgraduate students at its MSc in Highways and Transportation Engineering course. Unalike to University of Beira Interior, Coventry University admitting students from Africa, Asia, Middle East and Europe with multilingual students.

Among the common aspects in between both universities there are the organization of talks and seminars inviting experts in Civil Engineering domains and the public dissemination of research findings by students. These teaching methodologies allow the students to contact with other scientific, technical and cultural realities, preparing them for an international context.

Keywords: Multicultural Education, Planning and Transportation Engineering, Information and Communication Technologies.

\section{INTRODUCTION}

In a world characterized by increasing interconnectivity, diversity, and global mobility, many higher education institutions have adopted an internationalization strategy to stay competitive in the international education market. One of the fundamental objectives of the new teaching organization is to foster student mobility, mainly by supporting internationalization and multiculturalism trough promotion of international mobility of students, research scholars and staff [1]. Several studies emphasize the importance of multicultural teaching and learning environments as a pedagogical approach that is needed given the global changes and demands present in 21st century education [2], [3], [4].

According to Sánchez-Sánchez et al. [1], despite the efforts made so far to achieve international and multicultural curricula, the reality in most universities doing internationalization is however that the education of professionals, such as university teachers and dedicated staff officers are in the side-line of the system while they are potentially the key force capable of enhancing the entire system.

In this sense, a comparative analysis of teaching and learning methodologies in a multicultural environment of two European Universities with different dimension, background, sociocultural context and international student population is presented. The research is focused on the spatial planning and transportation engineering approaches, on the behalf of the Master Degree in Civil Engineering (MDCE) offered by the University of Beira Interior in Covilhã (Portugal) and the MSc in Highways and Transportation Engineering course of Coventry University in the United Kingdom. A pivotal attention will be put at the use of information and communication technologies aiming to improve the students' digital literacy and their required level of internationalization. 


\section{MULTICULTURAL EDUCATION}

Multicultural education is based on the student-centered approach of teaching, which refers to a teacher oriented method, with an autonomous, independent and critical thinking learning ([5] apud [6]). Involves fostering and inclusive climate in the classroom and a sense of community among international and local students, facilitating student learning with the use of diverse pedagogies, techniques and materials.

Banks [7] summarizes the goals and process of multicultural education into five dimensions: content integration, knowledge construction, prejudice reduction, equity pedagogy, and empowering school culture. Yusupova et al. [4] refers that multicultural environment can be considered in different ways: as a cultural phenomenon and a transfer mechanism of social experience, as the scope of pedagogical values, as a part of pedagogical culture of the lecturer and as a new informational environment.

Studies on the students' and scholars' perceptions of the influence of multiculturalism on high education teaching and learning practices point to the importance of including topics from different countries (of different international students) in the study programs, and creating chances of interaction and knowledge sharing for both international and local students promoting the discussion of topics at international level, stronger critical thinking skills and an inclusive learning environment [2], [3]. Some common obstacles perceived by scholars include the lack of knowledge of multicultural content, not having enough time to build and add such content, and the lack of formal training in multicultural pedagogy [2]. However, this can also be seen as an opportunity for scholars to update content with international topics.

According Johnson and Inoue [8], courses that take a multicultural approach to teaching and learning are best equipped to give students a broader, more complex understanding of the world into which they will enter after they exit the academy.

In Portuguese context, it can be said that the upward dynamic suggests a national commitment with student mobility [9], and consequently with multicultural education. This is equally evident in the recent Portuguese Higher Education Internationalization Strategy in which mobility, alongside with institutional strategic partnerships and development of digital education are pointed as key actions [10].

Located in a medium-sized city in the inlands of Portugal (Covilhã), UBI is a young public university with approximately 7300 students (2017). Is one of the 150 best institutions of Higher Education in the world in Times Higher Education (THE) Young University Rankings, which analyses and classifies academies under 50 years. In the "2018 Times Higher Education Engineering and Technology" appears in the range $251-300$ of a total of 500 listed institutions.

In accordance with the Portuguese international student mobility evolution [11], the number of international students has been growing at UBI, representing in $201715 \%$ of the student population [12]. In view of this trend, the UBI's service structure is prepared to support mobility and integration of UBI international community through the Internationalization and Career Department, the Social Action Services and the Language Lab, that offers free courses of English and assures the teaching of Portuguese to foreigners.

Coventry city has been awarded the title of City of Culture 2021 in the UK City of Culture competition run by the Department of Culture Media and Sport every four years. Coventry won the title because of a history of reinventing itself and being a city of peace and innovation. Coventry hosts many multicultural events such as Museum of the Moon to Crafts of the Punjab, Cinderella and so much more. The city also hosted over 50 hours of workshops with artists, cultural and voluntary organisations. Coventry University as the hub of multicultural diversity provides versatile learning activities for international students and thriving entertainment and social events as well as support to international students on a range of issues such as finance, housing and employment.

For virtual mobility experiences, Coventry University develops Online International Learning (OIL) projects. These OIL projects are included within the academic curriculum and provide staff and students with an opportunity to interact with international universities and industry professionals. University staff can use OIL projects to develop student's intercultural competences and digital skills, while working with others on subject-specific learning tasks or activities. OIL projects have delivered internationally recognised success in recent years. In 2016, Coventry University won a Gold Award in the Reimagine Education 2016: Discipline Awards! The award was won in the Arts and Humanities 
category for the Coriolanus Online project, which celebrated William Shakespeare through immersive telepresence-enabled virtual mobility. Coventry University students were also winners in The Guardian's Employability Initiative category, for their Seed project. The Seed project aimed to tackle the difficulty that international students often have in getting work experience. Seed addressed the problem by putting students into multidisciplinary and multicultural teams and gave them real world projects to work on in collaboration with organisations.

OIL Projects can take place in 'real-time' so that students from different countries are communicating and interacting 'live' at the same time. However, projects can also take place 'asynchronously', which means students from each country can interact and work together at different times. This may be helpful when time differences between countries are not manageable.

Participating in an OIL project can be key to getting work experience that, as an international student, may otherwise be difficult to get. Students get the opportunity to (1) interact, engage and collaborate with people that you would have not otherwise have the chance to work with; (2) share knowledge of your culture and ways of living, as well as learning about other people's; (3) learn about different communication styles, including non-verbal communication and body language; and (4) develop digital skills that are key to life in the 21st Century, especially those that will enable you to participate in team-work involving industry professionals from all over the world.

Coventry University is a national leader in the field of student support in mathematics and statistics, with over 30 years' experience. It is delivered by a small but committed team called sigma, which offers all Coventry University students a safety net and an additional level of help over and above their normal teaching. Students can just drop-in to the Mathematics Support Centre (MSC) in the Library to receive face-to-face tutoring in a welcoming, friendly and supportive environment. The service is free and no booking is required. In addition, sigma's Statistics Advisory Service offers hour-long appointments and workshops for in-depth help with statistics to final-year undergraduates and postgraduate students. The MSC is typically open for six hours each weekday in term time and there is a weekend service too. Reference books covering most students' mathematical needs are available to read in the Centre, and PCs are provided to access online resources or mathematical software. Students can also take away hand-outs to help them fill in any gaps in their mathematical knowledge. Sigma, which was designated as a Centre for Excellence in Teaching and Learning, won the prestigious national Times Higher Education award for Outstanding Support for Students in 2011.

\section{MULTICULTURAL EDUCATION IN PLANNING AND TRANSPORTATION ENGINEERING}

\subsection{The MSc in Civil Engineering at UBI: Planning and Transportation Approach}

Currently, Portuguese civil engineering slowly begins to recover from the international crisis that led to an investment breakdown on construction, which had as a consequence a large decrease of local candidates for civil engineering courses offered by higher education institutions. To minimize this situation, UBI has invested in recent years in attracting international students, resulting in classrooms essentially composed of international students.

The different backgrounds of international students, mainly coming from the old Portuguese colonies (Portuguese language speakers), such as Brazil (in south America), Angola, Cape Verde Islands, St Tomé and Principe (in Africa) or East Timor (in Asia); and the non-Portuguese speakers such as the ERASMUS students coming from the European countries, Turkey or more recently from Algeria, Iran or Syria, led to the need of rethinking the teaching methodologies in order to meet with the multicultural classroom environment. In this sense, the scholars responsible for the master degree in civil engineering are carrying out several strategies in order to improve the adaptation and the performance of these students, regarding the higher educational Portuguese system. Figure 1 shows the countries of origin of international students for the last 5 academic years.

The master is organized according to Bologna process and comprises a set of ten academic semesters along a five years' graduation course, allowing the students to tailor their study plan on their own interests and to highlight the theoretical and practical aspects of distinct civil engineering domains. In this way, students can select one of two specialization areas (Geotechnical and Environment or Structures and Construction), have optional units available in the 1st semester of year 5 , and choose their dissertation topic in the last year. 


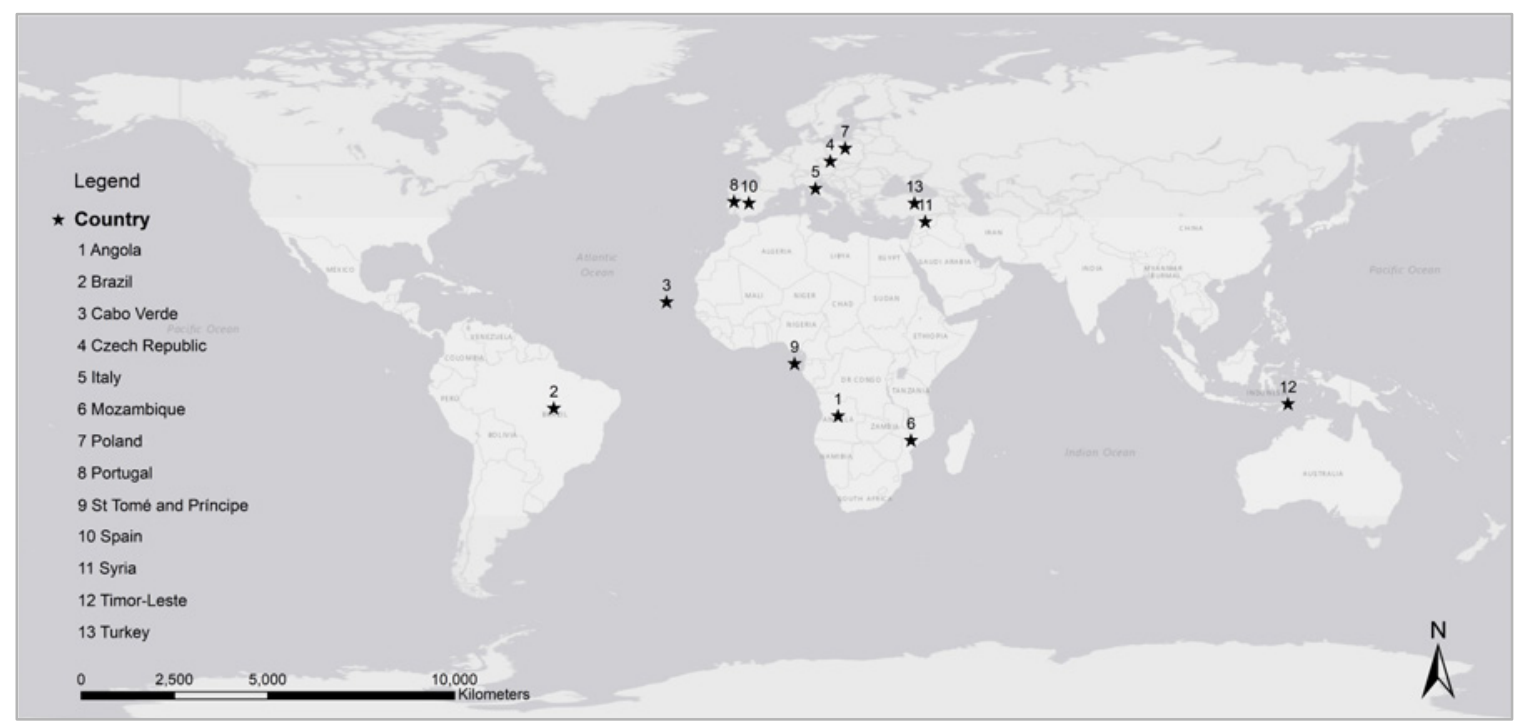

Figure 1. UBI - MDCE international students StoryMap

Table 1 presents the spatial planning and the transportation engineering units of the master programme as well as the optional units available for students wishing to continue their studies at the doctorate level.

Table 1. Planning and Transportation Engineering curricular units in UBI-Civil Engineering Programmes

\begin{tabular}{|c|c|}
\hline $\begin{array}{l}\text { Integrated Master Degree } \\
\text { ( } 5 \text { years) }\end{array}$ & $\begin{array}{l}\text { Doctor Degree } \\
\text { (3 years) }\end{array}$ \\
\hline Year 1, 2 and 3 (for all students) & Year 1 \\
\hline $\begin{array}{l}\text { - Urban and Regional Planning }\left(2^{\text {nd }} \text { year }\right) \\
\text { - Roads }\left(3^{r d} \text { year }\right)\end{array}$ & $\begin{array}{l}\text { - e-City Research and Methodologies* } \\
\text { - Transport Infrastructure Engineering* } \\
\text { - } \text { Mobility and Transport* }^{*}\end{array}$ \\
\hline $\begin{array}{c}\text { Year } 4 \text { and } 5 \\
\text { (for students attending Geotechnical and Environment } \\
\text { Specialization) }\end{array}$ & Year 2 and 3 \\
\hline $\begin{array}{l}\text { - Complements of Roads* }\left(5^{\text {th }} \text { year }\right) \\
\text { - Transport and Sustainable Urban Mobility }{ }^{*}\left(5^{\text {th }} \text { year }\right) \\
\text { - Master Dissertation or Project }{ }^{* *}\left(5^{\text {th }} \text { year }\right)\end{array}$ & - Thesis - Civil Engineering ${ }^{* *}$ \\
\hline
\end{tabular}

* Optional Unit

${ }^{* *}$ For students who choose to develop their end-of-cycle work in the area of planning or transportation

\subsubsection{Spatial planning engineering using ICT as research skills}

In terms of spatial planning approach, the learning and teaching methodologies in order to advance a multicultural environment, used at the Master Degree in Civil Engineering at the University of Beira Interior have their roots in recent years, when the foreign students started to be the majority in the classroom.

Pivotal attention has been put on the use of information and communication technologies (ICT), in order to improve student digital literacy. The multicultural environment is essentially a result of the presence of students from the Portuguese speaking countries (African countries such as Angola, Cape Verde Islands or St Tomé and Principe, East Timor in Asia or Brazil). They are the basis of a challenge in terms of teaching methodologies related to their lack of English language skills. Thus, the use of ICT in spatial planning realm is a way of bringing students to an international context, based on the control of two skills: the English and the computing as pivotal academic languages of communication at the higher level of education. 
These methodological approaches, on behalf of spatial planning domain, are strongest regarding the post-graduation programmes, considering master degree courses, whether in architecture or in civil engineering. The examples are the software created on purposes to monitoring the assessment of vernacular buildings in sensitive territories in terms of spatial planning ordinances, such as natural protected areas. These buildings refer to two examples, the wooden stilt-houses along to river banks and the limestone houses in forest mountain zones. They are organized in small urban settlements with their roots in the rural society, when there were no spatial planning rules, considering the urban development process. Regarding their localization in a flood zone, in the case of the wooden stilthouses, or in forest mountain, in the case of the limestone houses, they are in a very sensitive situation in spatial planning terms, because they belong to the ecological or to the agriculture national reserve which are areas where the construction of buildings is not allowed or is very restricted. However, the architectural features of these vernacular wooden or limestone houses and the morphological qualities of the small urban settlements near to the river (in the first case) or in the mountains (in the second) are very particular case studies with scientific interest. That's why they are included in the urban planning subject contents. For both case studies a software was created in order to evaluate the buildings conditions.

The referred software allows the analysis of results regarding the buildings needs for immediate intervention, the performance of status of buildings conservation (e.g. [13]) and their proximity to the vernacular architectural matrix.

A challenge in this approach was to design a method, using a software computer programme, regarding the features of vernacular architecture, having as case study real stilt-houses of river banks (e.g. [14]) and real limestone buildings in the mountain zones. In the first case the case study area of the software application was the wooden stilt-house villages of Tagus river banks, comprising a set of about 90 buildings and in the second case, the case study area was the limestone-house village of Serra de Santo António (St. Antony Mountain), both in the central region of Portugal.

The novelty was to adapt an evaluation model as a diagnosis methodology suitable for vernacular architecture. In this process, there is a step of testing the software algorithms in order to be very well adapted to the characteristics of each case study. Therefore, the software was tested in a sample of few building in order to be calibrated. The final version of the software was tested in the referred case studies. The first evaluation using the software was done in 2014 on the behalf of a PhD thesis in Architecture analysing the wooden stilt-house villages and the second in 2016 on Master Dissertations, three in Civil Engineering and two in Architecture, each one of them analysing one of the referred villages (e.g. [15], [16]).

Based on the knowledge resulting from the software focused on the wooden stilt-houses, a second software was created in 2018 to evaluate the limestone-house village of St. Antony Mountain which is an ongoing project, being developed in a Master dissertation in Civil Engineering.

The existence of software as a methodological approach in spatial analysis has the advantage of being able to be used again for the study of similar buildings, by national or international students, including non-Portuguese speakers, given that it was designed in an English version and a friendly way for users.

In this sense, the use of software tools in English, based on the presented examples is spread in the literature (e.g. [17], [18], [19]) as a universal language, supporting teaching methodologies in spatial analysis. The result is an exhaustive survey of buildings and territories, a guideline for future spatial planning policies and strategies, and the chance of using the software in other similar case studies in other countries, considering the wide range of backgrounds of international students.

\subsubsection{Transportation Engineering}

The students are introduced to aspects related to transportation engineering in the 2 nd semester of year 3, within Roads course unit. In this course, they are provided with theoretical and practical knowledges and skills, required to perform a proper analysis and selection of road location, analysis of road traffic conditions and road project design. This unit has continuity in the 1st semester of the 5th year for students attending the optional units of Complements of Roads and Transport and Sustainable Urban Mobility. The Complement of Roads unit aims to prepare students for the design and processing aspects of the construction, maintenance and safety of roads, and Transport and Sustainable Urban Mobility aims to provide students with theoretical knowledge on the analysis and planning of mobility systems in urban areas. Additionally, a GIS unit provides theoretical and practical 
skills about spatial representation and geo-referenced information analysis that can be applied to Transportation Engineering.

The pedagogical contents of the units are linked and consecutive, meaning that in the end of the master's programme, students should be able to analyse road operation conditions, to design new road infrastructures (urban and interurban) and to manage the maintenance of the infrastructure.

International students are integrated in these courses in the same classes as the Portuguese students, and consequently, there was a need to adapt the teaching methodology to the multicultural environment of the classroom. In this sense, a student-centred pedagogy based in group Project Based Learning (PBL) was adopted. PBL method uses problems as a starting point for the acquisition and integration of new knowledges [20]. This type of learning is in line with what Goodhew [21] apud Kapranos [22] defines as fundamental points for a good engineering education. In practical terms, the transportation engineering scholars' structure and plan the activities and students are expected, having in account their different perspectives and backgrounds, to raise, discuss, implement and evaluate transport projects with applications in the real world. Students are also encouraged to address some theoretical and practical topics of the course through a diverse set of bibliographic references analysis from different countries (individually and in groups), under the scholar supervision, and to present and discuss the main findings in the classroom in English. This methodology also facilitates the understanding about transversal skills, such as searching information, writing technical reports, teamwork, results presentation and English communication. One of the strongest results of this experience that can be observed is the increasing of students' autonomy and critical scientific thinking.

Regarding ICT tools, they are available online and are used in the teaching/learning process to consult, research and communicate information. UBI Moodle web platform, file storage/synchronization/share services, service B-on: Online knowledge library, scientific data bases, web sites, and university library web site are some of the tools used in the scope of Transport Engineering units. Other activities as student site visits, work findings public presentation and participation in competitions, awards for students, talks and seminars, national and international congress are also encouraged.

A special attention is put to the aspects related to the low English proficiency, the lack of educational skills in dealing with scientific documents, digital information and communication tools, and the different approaches about citations that can lead to unintentional plagiarism [23]. The latter is addressed from an educational perspective (rather than punitive) thought an extracurricular lecture and workshop [24]. The lecture is dedicated to how to cite, paraphrase and reference, while the workshop instructs in the use of bibliographic references management tools available online.

As final remark, it can be said from the Transportation Engineering scholars experience that the integration in small classes (15 students), multicultural support materials, visual teaching tools, classes taught in English, and the use of ICT have shown favourable results for both host and international students and promote an inclusive and friendly learning environment.

\subsection{The MSc in Highways and Transportation at Coventry University}

Coventry University has started the MSc in Highways and Transportation Engineering course on October 2016. Accreditation is currently being sought from the Joint Board of Moderators (JBM) to be approved as 'further learning' for Chartered Engineer (CEng) status. Students in this course are developing high-level knowledge, wide-ranging understanding and professional skills in:

- Properties of pavement materials and sustainability issues,

- Optimum design of pavements of different generic types,

- Appropriate techniques, processes and management strategies for pavement evaluation, maintenance and strengthening,

- Principles of highway alignment and geometric design, covering both links and junctions as well as junction capacity analysis,

- Stability and performance of earthwork systems,

- Traffic flow theory and traffic signal control, picking up on traffic signal technology, 
- Key principles of traffic micro-simulation modelling and of the planning situations for which such approaches are suitable,

- Policies and key principles of sustainable transport,

- Detailed design of bridges,

- Systems theory to the management of projects in the highways and transportation sector,

- Key principles of safety engineering, with specific reference to CDM2015,

- Regulatory and legal framework within which the highways and transportation sector highways and transportation sector operates,

- Procurement systems and standard forms of construction contracts,

- Key principles of safety and health in the construction workplace

Launching on October 2016, the MSc in Highways and Transportation Engineering course has experienced a significant enrolment of international students. Most of the students enrolled in this course are international students coming from Europe, Asia, Africa, and Middle East (Figure 2).

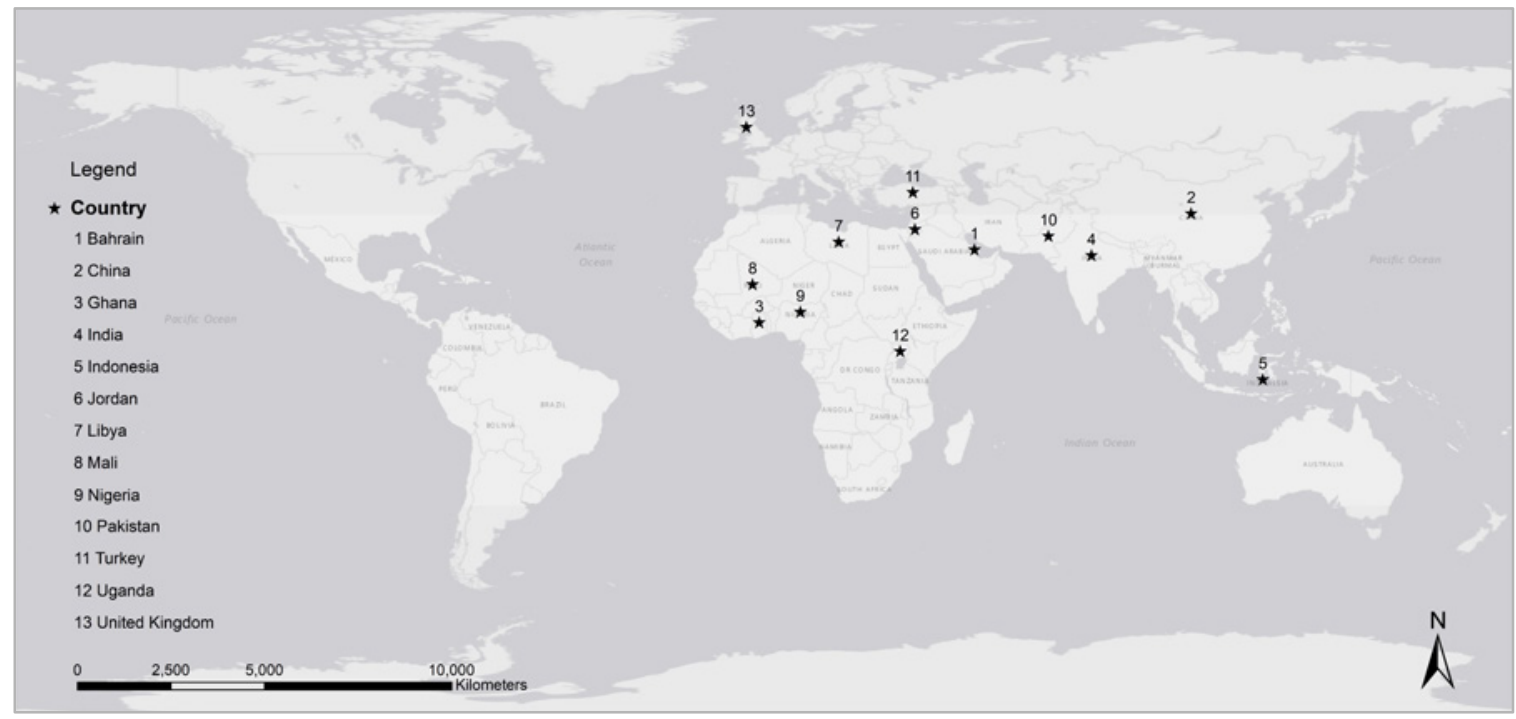

Figure 2. Coventry - MHTE international students StoryMap

To facilitate the learning objectives of this course, Coventry University provides a wide range of resources and facilities. Lecture materials used in the classroom including handouts, assignments, etc. are published on the course website (Moodle). In the web Moodle, some lecturers make their lecture slides available prior to lectures so that students can print them out before the lecture; others provide a range of information that will be useful to your study, e.g. web links, additional information or coursework advice. Students can email the Module Leader and other students studying the module and can also take part in Discussion Forum debates. Module Leaders post important announcements and notices in Moodle; some modules have class tests while others provide multiple-choice tests for self-assessment. It is essential that students incorporate Moodle into learning routines and check the study webs at regular intervals. It should be noted that just as different teachers have different styles, Module Leaders will use Moodle in different ways.

Moodle is designed to enhance learning and for most modules (with the exception of some distance learning modules) the information provided is meant to be used in addition to attendance at lectures, seminars and workshops: it is not a replacement for these. Non-attendance of scheduled classes will limit and damage understanding of module content. Moodle Discussion Fora are a valuable resource and because they are open to others taking the module or course they must be used appropriately. They are not general chat rooms and should not be used as such. As Moodle fora are academic fora, it is important to write in normal, proper English and not text speak. If students have a complaint or problem, they must think very carefully about how to discuss/raise this, especially if going public with an issue. 
The School of Energy, Construction and Environment periodically organise seminar series inviting practitioners, professional organisations and academia to discuss on projects, problems and solutions related to transportation and highway engineering and planning topics and projects. Guest speakers share their experience and expertise with students that give them an opportunity to see the insight and perspective of the guest speaker's particular field. Moreover, students can link the taught lecture materials with the real-world projects and experiences. Organizing this type of interactive events promotes the close association of students with the transport industries, professional organisations and professors from other universities; acquaints students with topics of interest in transportation engineering and planning, fosters the development of professional spirit and promotes common interests among students. Moreover, students can share their professional concerns with the professional organisations and transport industries that can contribute to their personal growth and career development and increase the student's sense of fellowship with the transport community.

\section{COMPARATIVE ANALYSIS AND MAIN OUTCOMES}

UBI was founded in 1973 and can be considered as a young institution located in a $\approx 51000$ inhabitant's city (considering the municipality as a whole, Census 2011) whilst UCoventry is a consolidated institution with 175 years old located in a $\approx 317000$ inhabitant's city.

In a country-level vision in which UBI fits in, the main attractive power of Portuguese institutions for Erasmus students is explained by its location, climate, and leisure opportunities [9], while the language, security and employability are the main drivers for the non-Erasmus students. UBI's international student community is mainly from Europe and Portuguese-speaking countries. Due to its proximity, it also attracts many Spanish students. The international student population at UBI presents different levels of mastery of the English language, mainly when comparing the European student's skills with the Portuguese-speaking countries international student's skills.

UCoventry is characterized by international students mainly from English-speaking countries (UK excolonies and protectorates from Africa or Asia). English is the main language in scientific research and dissemination nowadays, which gives English-speaking universities a tremendous advantage attracting the best students and scholars from all over the world. This feature favours networking enhancing the quality and prestige of these institutions. UCoventry adds to this advantage a close connection to the design industry.

The comparative analysis of the multicultural environment of the two Universities showed that despite different dimension, background, sociocultural context and international student population, there are similar teaching and learning approaches in both institutions.

Since engineering graduates will almost certainly work in teams, possibly in an international environment, group or team work is assumed as a significant part of the engineering multicultural education, which fits in a student-centred Project-Based Learning methodology.

As teaching strategies, scholars regularly update contents from an international perspective, encourage students to research, communicate and discuss technical-scientific information from different backgrounds, and promote international knowledge exchange through seminars and conferences. These strategies foster an inclusive classroom environment and enhance the level of internationalization of both scholars and students.

ICT are also used in the two contexts to assist the teaching, learning and communication process between teacher/student and host/international student (networking), enhancing digital literacy, that has increasingly becoming an essential issue in education, life and workplace success. Students are in general keen on using ICT tools, thus, the use of computing technologies such as softwares in English or Moodle web platforms is a way of keeping their interest, helping them to improve their academic skills and to achieve their academic goals.

\section{CONCLUSIONS}

One of the first lessons learned, from the most recent years dealing with international students, regarding the Master Degree in Civil Engineering at UBI, is that the multicultural environmental in the higher level of education is bringing challenges for scholars. These challenges are based on the needs of rethinking the methodological approaches in each academic year, considering the students' backgrounds and their research interests. In this sense, ICT tools and academic material in English 
are a good way of having a universal language, able to be used and understood by all students and to be applied to case studies coming from the international students' home countries.

Another lesson is that the existence of a multicultural environment in the classroom, with students from different continents, countries, University systems or sociocultural backgrounds, is an advantage given the wider range of input knowledge that results in better and more international outputs.

As future directions, particular institutional attention should be paid to scholars training in multicultural pedagogy, to the improve of English proficiency, to students training in correct citation of bibliographic sources and to a better and more efficient use of ICT in the overall learning process.

\section{ACKNOWLEDGEMENTS}

The authors acknowledge University of Beira Interior, Coventry University, CERIS-CESUR, C-MADE and CITTA for supporting the performed study.

Part of the work was supported with Portuguese national funds by FCT - Foundation for Science and Technology within the UID/ECI/04082/2013 project.

\section{REFERENCES}

[1] L. C. Sánchez-Sánchez, S. Salaberri, and M. del M. Sánchez-Pérez, "Multiculturalism and Internationalization in Spanish Universities: ¿North-south Socio-cultural Differences?," Procedia - Soc. Behav. Sci., 2017.

[2] S. M. Bigatti et al., "Faculty Perceptions of Multicultural Teaching in a Large Urban University," J. Scholarsh. Teach. Learn., vol. 12, no. 2, pp. 78-93, 2012.

[3] A. Pandian, S. B. Baboo, and O. H. A. Mahfoodh, "Influence of multiculturalism on the study programs in Malaysian public universities: international students' perceptions," Stud. High. Educ., 2016.

[4] G. F. Yusupova, J. Podgorecki, and N. G. Markova, "Educating young people in multicultural educational environment of higher education institution," Int. J. Environ. Sci. Educ., 2015.

[5] M. Elmgren and A.-S. Henriksson, Academic Teaching, 1st ed. Lund: Studentlitteratur, 2014.

[6] J. Safipour, S. Wenneberg, and E. Hadziabdic, "Experience of Education in the International Classroom-A Systematic Literature Review," J. Int. Students, vol. 7, no. 3, pp. 2166-3750, 2017.

[7] J. a. Banks, "Multicultural Education," in Handbook of Research on Multicultural Education, 2004.

[8] K. Johnson and Y. Inoue, "Diversity and Multicultural Pedagogy: An Analysis of Attitudes and Practices within an American Pacific Island University," J. Res. Int. Educ., 2003.

[9] C. Sin, O. Tavares, and G. Neave, "Student Mobility in Portugal: Grappling With Adversity," J. Stud. Int. Educ., vol. 21, no. 2, pp. 120-135, 2017.

[10] Ministério da Educação e Ciência, "Uma Estratégia para a Internacionalização do Ensino Superior Português," p. 166, 2014.

[11] OCDE.Stat, "International Student Mobility," tertiary mobile envolment. [Online]. Available: https://stats.oecd.org/Index.aspx?DataSetCode=EAG_ENRL_MOBILES_ORIGIN. [Accessed: 05-May-2018].

[12] University of Beira Interior, "Consolidated Annual Report and Accounts 2017," Covilhã, 2017.

[13] A. Virtudes and F. Almeida, "ICT Method for Evaluation of Heritage Buildings Conservation," in Procedia Engineering, 2016.

[14] F. Almeida and A. L. Virtudes, "ICT for smart evaluation of vernacular architecture in a stilthouse village," Open Eng., 2016.

[15] A. Virtudes et al., "Monitoring the assessment of vernacular buildings using an ICT method," $J$. Civ. Eng. Archit. Res., vol. 4, no. 2, pp. 1904-1912, 2017. 
[16] A. Virtudes et al., "Teaching Methodologies using ICT: Vernacular Architectural Territories," in Local+Global, Innovative Symbioses in Architectural Education, 2017, pp. 152-157.

[17] A. Virtudes, I. Rodrigues, B. Santos, and M. Pop, "Teaching Methodologies in Civil Engineering: a multidisciplinary approach," in National Technical-Scientific Conference, 17th ed.: Modern Technologies for the 3rd Millennium, 2018.

[18] A. Virtudes and V. Cavaleiro, "Teaching Methodologies in Spatial Planning for Integration of International Students," in IOP Conference Series: Earth and Environmental Science, 2016.

[19] A. Virtudes and F. Almeida, "Educational research in architecture: ICT tool for historical buildings evaluation," Int. J. Syst. Appl. Eng. Dev., pp. 282-285, 2016.

[20] H. S. BARROWS, "A taxonomy of problem-based learning methods," Med. Educ., vol. 20, no. 6, pp. 481-486, 1986.

[21] P. Googdhew, "Teaching Engineering: Can we do it better?," in Proceedings of 4th International Symposium for Engineering Education, 2012, pp. 1-7.

[22] P. Kapranos, "Teaching and Learning in Engineering Education - Are We Moving with the Times?," Procedia - Soc. Behav. Sci., vol. 102, no. Ifee 2012, pp. 3-10, 2013.

[23] J. Gunnarsson, W. J. Kulesza, and A. Pettersson, "Teaching International Students How to Avoid Plagiarism: Librarians and Faculty in Collaboration," J. Acad. Librariansh., vol. 40, no. $3-$ 4, pp. 413-417, 2014.

[24] J. Goncalves, B. Santos, and P. Almeida, "Do Students in Higher Education Know the Real Meaning of Plagiarism?," in Edulearn14: 6th International Conference on Education and New Learning Technologies, 2014. 